\title{
Implementation and design of new low-cost foot pressure sensor module using piezoelectric sensor in T-FLoW humanoid robot
}

\author{
R. Dimas Pristovani ${ }^{1}$, Dewanto. Sanggar ${ }^{2}$, Pramadihanto. Dadet ${ }^{3}$ \\ ${ }^{1}$ Department of Electrical Engineering, Politeknik Elektronika Negeri Surabaya, Indonesia \\ ${ }^{2}$ Department of Mechatronics Engineering, Politeknik Elektronika Negeri Surabaya, Indonesia \\ ${ }^{3}$ Department of Computer Engineering, Politeknik Elektronika Negeri Surabaya, Indonesia
}

\begin{tabular}{l} 
Article Info \\
\hline Article history: \\
Received May 4, 2018 \\
Revised Aug 8, 2018 \\
Accepted Aug 23, 2018 \\
\hline
\end{tabular}

\section{Keywords:}

Center of pressure

Force resultant

Humanoid robot

Landing detection

Piezoelectric sensor

Robotics

Zero moment point

\begin{abstract}
Basically, human can sense the active body force trough the soles of their feet and can feel the position vector of zero moment point (ZMP) based on the center of pressure $(\mathrm{CoP})$ from active body force. This behavior is adapted by T-FLoW humanoid robot using unique sensor which is piezoelectric sensor. Piezoelectric sensor has a characteristic which is non-continuous reading (record a data only a moment). Because of it, this sensor cannot be used to stream data such as flex sensor, loadcell sensor, and torque sensor like previous research. Therefore, the piezoelectric sensor still can be used to measure the position vector of ZMP. The idea is using this sensor in a special condition which is during landing condition. By utilizing 6 unit of piezoelectric sensor with a certain placement, the position vector of ZMP (X$\mathrm{Y}$-axis) and pressure value in Z-axis from action body force can be found. The force resultant method is used to find the position vector of ZMP from each piezoelectric sensor. Based on those final conclusions in each experiment, the implementation of foot pressure sensor modul using piezoelectric sensor has a good result (94\%) as shown in final conclusions in each experiment. The advantages of this new foot pressure sensor modul is low-cost design and similar result with another sensor. The disadvantages of this sensor are because of the main characteristic of piezoelectric sensor (non-continuous read) sometimes the calculation has outlayer data.
\end{abstract}

Copyright (C) 2019 Institute of Advanced Engineering and Science. All rights reserved.

\section{Corresponding Author:}

R. Dimas Pristovani,

Department of Electrical Engineering,

EEPIS Robotics Research Center (ER2C)-Politeknik Elektronika Negeri Surabaya (PENS),

St. Raya ITS, Keputih, Sukolilo, Surabaya, 60111, Indonesia.

Email: dimaspristovanir@pasca.student.pens.ac.id; dimaspens@gmail.com

\section{INTRODUCTION}

Generally human behavior was adapted in many systems which has special requirement in each part such as mechanical design (body design, kinematics, dynamics, or mechanic characteristic) and control design (PID control, fuzzy control, or neural network). In T-FLoW humanoid robot system has several special requirements. T-FLoW humanoid robot is humanoid robot from EEPIS Robotics Research Center (ER2C) Laboratory. T-FLoW humanoid robot has 28 Degree of Freedom (DoF) version and teen size of mechanical body. In the development of T-FLoW humanoid robot, there is one behavior which will adapted by T-FLoW humanoid robot and will discuss in this paper as shown in Figure 1. This behavior is sense the active body force trough the soles of their feet. In humanoid robot, the behavior to sense the active body force trough the soles of the feet are same as with directly measuring the position vector of Zero Moment Point (ZMP) based on Center of Pressure (CoP) [1-3].

In previous research, there are several sensors which normally used in humanoid robot such as Force Sensing Resistant (FSR) sensor [4, 5], LoadCell sensor [6], and F/T sensor and several methods to obtain the 
position vector of ZMP based on the sensor usage such as fuzzy and clustering (AI) [7-13]. Based on previous research before, this paper will discuss about how to measure the position vector of ZMP using a unique sensor which is piezoelectric sensor.

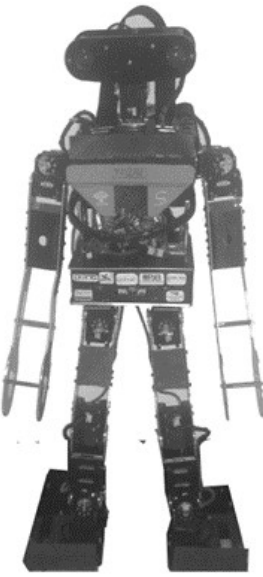

(a)

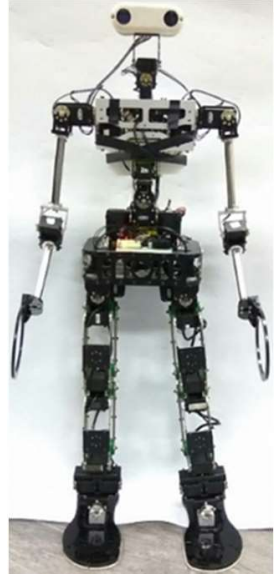

(b)

Figure 1. T-FLoW humanoid robot (a) Serial mechanism version (20 DoF) (b) Parallel mechanism version (28 DoF)

Piezoelectric sensor is very unique sensor which has a characteristic non-continuous reading (record a data only a moment) when receive a single continuous pressure (non-polarization process) [14-31]. Because of it, this sensor cannot be used to stream data such as flex sensor, loadcell sensor, and torque sensor like previous research [7-13]. Therefore, the piezoelectric sensor still can be used to measure the position vector of ZMP. The idea is using this sensor in a special condition which is during landing condition. By utilizing 6 unit of piezoelectric sensor with a certain placement, the position vector of ZMP (X-Y-axis) and pressure value in Z-axis from action body force can be found. The force resultant method is used to find the position vector of ZMP from each piezoelectric sensor. Because the sensor placement is fixed, the force resultant method can be used to find the position vector of ZMP (X-Y-axis) and pressure value in Z-axis.

\section{RESEARCH METHOD}

The research method is describing about why and how the piezoelectric sensor is used to gain the position vector of ZMP based on CoP. Research method has several sub-sections which is piezoelectric sensor characteristic, piezoelectric sensor usage, resultant force method, design of foot sensor module, and hardware overview.

\subsection{Piezoelectric sensor characteristic}

Piezoelectric sensor has different characteristic with another pressure sensor as mentioned before. This section will explain about piezoelectric sensor characteristic. Piezoelectric is a material which transform the energy from mechanical domain into electrical domain or electrical domain into mechanical domain. This transformation process is called piezoelectric effect. Piezoelectric effect has 2 conditions based on transform domain. The example of piezoelectric effect is when piezoelectric material is applied with electricity (electrical domain), the piezoelectric material will vibrate (mechanical domain) and causing a sound. Another example is when piezoelectric material is applied with pressure, touch, or vibration (mechanical domain), the piezoelectric material will generate an electricity (electrical domain) with dynamic range based on the frequency and how strong the applied pressure, touch, or vibration.

Piezoelectric effect which has relation with this discussion is when piezoelectric material as shown in Figure 2 is transform the mechanical domain into electrical domain. The mechanical domain in this discussion is pressure force in the soles of the feet caused by active body force and the electrical domain is electricity which generated by piezoelectric material based on the applied pressure force as shown in Figure 3. 


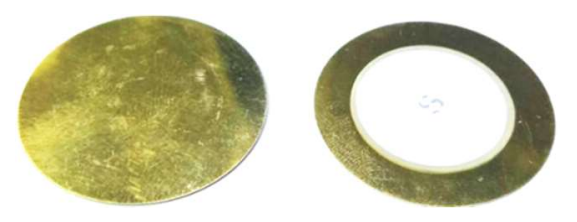

Figure 2. Piezoelectric sensor which used in T-FLoW humanoid robot

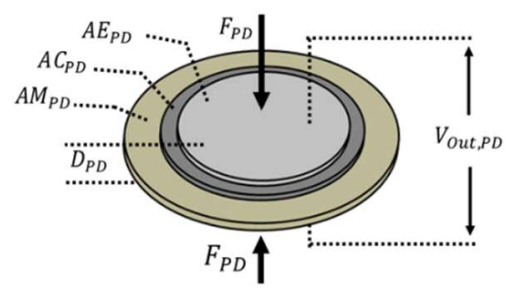

Figure 3. Piezoelectric sensor disc receives pressure force

The relation between pressures forces with generated electricity in piezoelectric sensor is shown in (1) shown based on Figure 3.

$$
V_{\text {Out }, P D}=\left(C_{P D} D_{P D} / C_{P D}^{T} A E_{P D}\right) F_{P D, A}
$$

Where:

$$
\begin{aligned}
& C_{P D}=d 33=13510^{-12} \mathrm{~m} / \mathrm{V} \\
& C_{P D}^{T}=\varepsilon 33 \times \varepsilon 0=800 \times 8.85410^{-1}=7083.210^{-12} \mathrm{~F} / \mathrm{m} \\
& A E_{P D}=\pi r^{2}=3.14 \times 0.9^{2}=2.5434 \mathrm{~cm}^{2} \\
& D_{P D}=0.2 \mathrm{~mm}=0.02 \mathrm{~cm}
\end{aligned}
$$

Where $F_{P D, A}$ is applied pressure force. $D_{P D}$ is thickness of piezoelectric sensor. $A E_{P D}, A C_{P D}$, and $A M_{P D}$ is wide area of piezoelectric electrode, material, and metal. $C_{P D}$ and $C_{P D}^{T}$ is piezoelectric constant (based on material). $V_{O u t, P D}$ is generated voltage caused by applied pressure force

\subsection{Piezoelectric sensor usage}

Based on the characteristic of piezoelectric sensor, this section will explain about how to use this sensor to obtain the pressure data. When piezoelectric material is used to transform the data from mechanical domain (pressure) into electrical domain (electricity), the pressure force must have a non-continuous pressure (polarization process/several pressure in a time domain) to generate a continuous electricity as shown in Figure 4. If the pressure force is continuous pressure (non-polarization process/single continuous pressure), the piezoelectric sensor has a single data reading with dynamics pick based on the how big applied pressure force as shown in Figure 5.

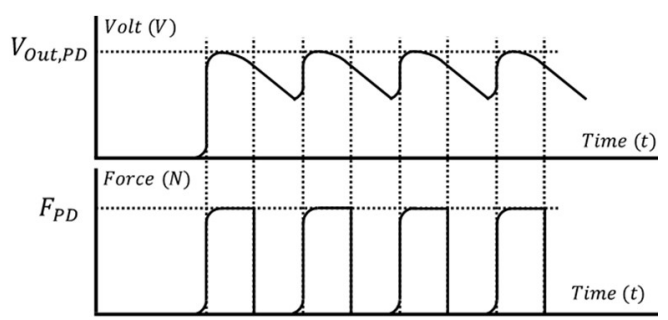

Figure 4. Comparison between non-continuous pressure (polarization process/several pressure in a time) with generated electricity of piezoelectric sensor 


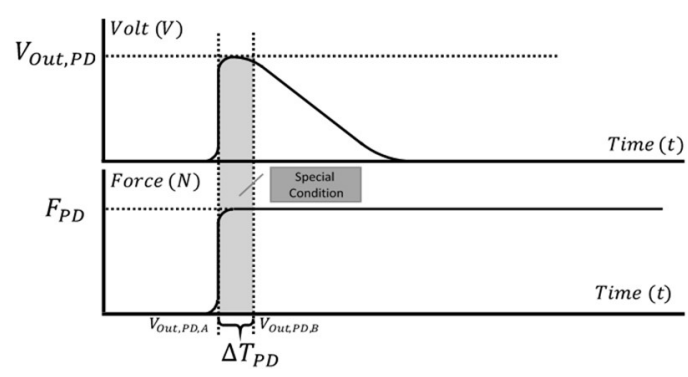

Figure 5. Comparison between continuous pressures (non-polarization process/single continuous pressure) with generated electricity of piezoelectric sensor

Because of it, the piezoelectric sensor has opposite usage and opposite characteristic from another pressure sensor such as FSR, LoadCell, and F/T sensor. Therefore, the piezoelectric sensor still can be used to obtain the position vector of ZMP as result of this discussion. The idea to achieve this result is, the piezoelectric sensor is used in a special condition as seen in Figure 5. The special condition is during landing condition (when feet of legs is touching the ground/base). As seen in Figure 5, the special condition has unequal data with highest and lowest peak. The data must be reconditioned to obtain the average data (2). The (3) is used to obtain the real applied pressure force $\left(F_{P D, M}\right)$ from average data of piezoelectric sensor $\left(V_{O u t, A v, P D}\right)$.

$$
\begin{aligned}
& V_{O u t, A v, P D}=\left(\sum_{V_{O u t, P D, A} V_{O u t, B}} V_{\text {Out }, P D}\right) / \Delta T_{, P D} \\
& F_{P D, M}=\left(C_{P D}^{T} A E_{P D} / C_{P D} D_{P D}\right) V_{O u t, A v, P D}
\end{aligned}
$$

Where $V_{O u t, A v, P D}$ is piezoelectric sensor average output. $V_{O u t, P D, A}$ and $V_{O u t, P D, B}$ is upper and lower limit. $\Delta T_{, P D}$ is the difference between upper and lower limit. $F_{P D, M}$ is real applied pressure force from average data of piezoelectric sensor $\left(V_{O u t, A v, P D}\right)$. The piezoelectric sensor is placed in the soles of the feet. To obtain the position vector of ZMP, at least needs 3 unit of piezoelectric sensor [19]. In this discussion, T-FLoW humanoid robot will utilize 6 unit of piezoelectric sensor with a certain placement (fix placement). The data from these piezoelectric sensors $\left(V_{O u t, P D}\right)$ is combined and processed by using resultant force method to obtain the position vector of ZMP (X-Y-axis) and pressure value in Z-axis from action body force can be found.

\subsection{Resultant force method (non-parallel)}

Sometimes, a force usually has a certain angle $\left(\theta_{R, i}\right)$ from normal axis (X-Y-axis). The resultant force is how to transform this kind of force into force vector (X-Y-axis). The resultant force method has 2 kinds of calculation based on the force angle which can be seen in Figure 6 and Figure 7.

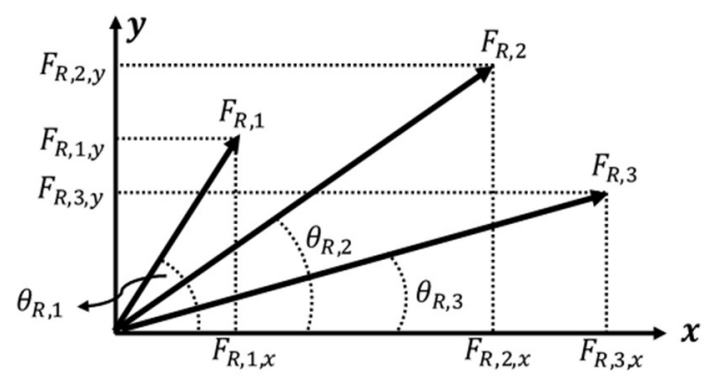

Figure 6. Resultant force calculation with uncertain force angle 
Figure 6 is explaining about the scalar force $\left(F_{R, i}\right)$ with uncertain angle $\left(\theta_{R, i}\right)$. This kind of scalar force has several force vectors based on scalar force value $\left(F_{R, i}\right)$ and the force angle $\left(\theta_{R, i}\right)$. Because of it, the force vector $\left(F_{R, i,(x, y)}\right)$ of this model is not linear (4).

$$
\theta_{R, i}=-\infty \leq \theta_{R, i} \leq \infty
$$

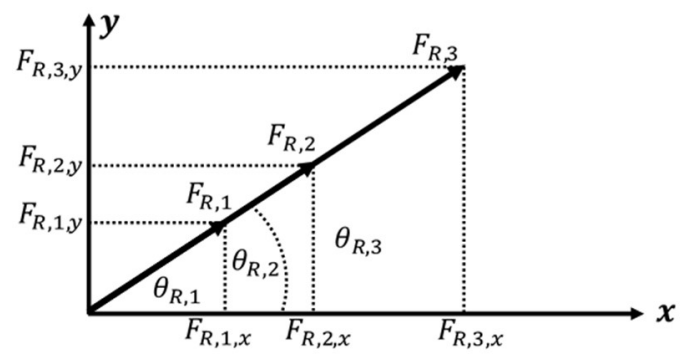

Figure 7. Resultant force calculation with certain force angle

Figure 7 is explaining about the scalar force $\left(F_{R, i}\right)$ with certain angle $\left(\theta_{R, i}\right)$. This kind of scalar force has force vectors only based on scalar force value $\left(F_{R, i}\right)$. Because of it, the force vector $\left(F_{R, i,(x, y)}\right)$ of this model is linear with scalar force value Equation (5).

$$
\theta_{R, i}=\text { Fix value }
$$

To transform the scalar force $\left(F_{R, i}\right)$ into force vector $\left(F_{R, i,(x, y)}\right)$ is used $(6)$. The equation can be used to calculate both of resultant force models above. The resultant force calculation with certain force angle model is used in this discussion because it has a fix position (fix force angle).

$$
F_{R, i}\left[\begin{array}{l}
x \\
y
\end{array}\right]=\left[F_{R, i}\left[\begin{array}{l}
\cos ^{-1} \theta_{R, i} \\
\sin ^{-1} \theta_{R, i}
\end{array}\right]\right]
$$

\subsection{Design of foot sensor module}

As mentioned before, the resultant force method is used to calculate the position vector of ZMP based on CoP from 6 unit of piezoelectric sensor. Each sensor has fixed placement in the soles of the robot feet as seen in Figure 8.
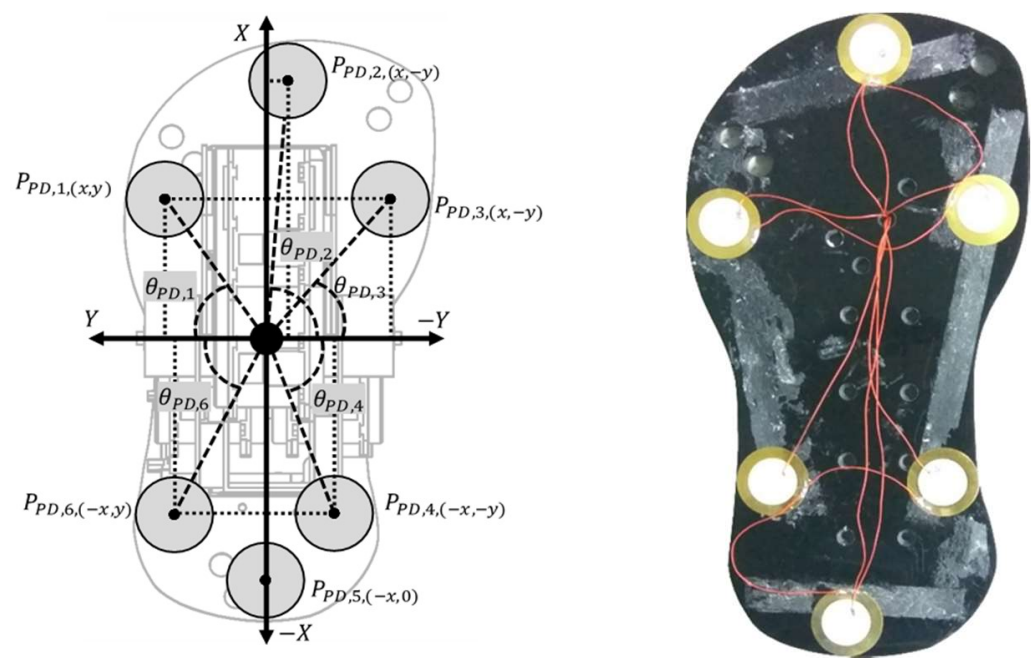

Figure 8. Piezoelectric sensor placement in the T-FLoW humanoid robot feet (A) Top view of design (B) Bottom view of T-FLoW feet 
Piezoelectric sensor will measure the vertical pressure force which happen in the feet of robot. To generate the position vector of ZMP and pressure value in Z-axis, each sensor is calculated by using Newton's Law with force resultant equation which explained in (7) or in (8 13).

$$
P_{P D, i}\left[\begin{array}{l}
x \\
y \\
z
\end{array}\right]=\left[\begin{array}{c}
F_{P D, M, i}\left[\begin{array}{l}
\sin ^{-1} \theta_{P D, i} \\
\cos ^{-1} \theta_{P D, i}
\end{array}\right] \\
F_{P D, M, i}
\end{array}\right]
$$

Where $P_{P D, i}$ is resultant force vector (X-Y-Z-axis) in a piezoelectric sensor. $F_{P D, i}$ is force value which applied in a piezoelectric sensor. $\theta_{P D, i}$ is certain angle of piezoelectric sensor point to the origin point of the robot feet. $i$ is the number of piezoelectric sensor in T-FLoW humanoid robot.

To obtain the force resultant in piezoelectric sensor $1\left(P_{P D, 1}\right)$ :

$$
P_{P D, 1}\left[\begin{array}{l}
x \\
y \\
z
\end{array}\right]=\left[\begin{array}{c}
F_{P D, M, 1}\left[\begin{array}{l}
\sin ^{-1} \theta_{P D, 1} \\
\cos ^{-1} \theta_{P D, 1}
\end{array}\right] \\
F_{P D, M, 1}
\end{array}\right]
$$

To obtain the force resultant in piezoelectric sensor $2\left(P_{P D, 2}\right)$ :

$$
P_{P D, 2}\left[\begin{array}{l}
x \\
y \\
Z
\end{array}\right]=\left[\begin{array}{c}
F_{P D, M, 2}\left[\begin{array}{l}
\sin ^{-1} \theta_{P D, 2} \\
\cos ^{-1} \theta_{P D, 2}
\end{array}\right] \\
F_{P D, M, 2}
\end{array}\right]
$$

To obtain the force resultant in piezoelectric sensor $3\left(P_{P D, 3}\right)$ :

$$
P_{P D, 3}\left[\begin{array}{l}
x \\
y \\
Z
\end{array}\right]=\left[\begin{array}{c}
F_{P D, M, 3}\left[\begin{array}{l}
\sin ^{-1} \theta_{P D, 3} \\
\cos ^{-1} \theta_{P D, 3}
\end{array}\right] \\
F_{P D, M, 3}
\end{array}\right]
$$

To obtain the force resultant in piezoelectric sensor $4\left(P_{P D, 4}\right)$ :

$$
P_{P D, 4}\left[\begin{array}{l}
x \\
y \\
z
\end{array}\right]=\left[\begin{array}{c}
F_{P D, M, 4}\left[\begin{array}{l}
\sin ^{-1} \theta_{P D, 4} \\
\cos ^{-1} \theta_{P D, 4}
\end{array}\right] \\
F_{P D, M, 4}
\end{array}\right]
$$

To obtain the force resultant in piezoelectric sensor $5\left(P_{P D, 5}\right)$ :

$$
P_{P D, 5}\left[\begin{array}{l}
x \\
y \\
z
\end{array}\right]=\left[\begin{array}{c}
F_{P D, M, 5}\left[\begin{array}{l}
\sin ^{-1} \theta_{P D, 5} \\
\cos ^{-1} \theta_{P D, 5}
\end{array}\right] \\
F_{P D, M, 5}
\end{array}\right]
$$

To obtain the force resultant in piezoelectric sensor $6\left(P_{P D, 6}\right)$ :

$$
P_{P D, 6}\left[\begin{array}{l}
x \\
y \\
z
\end{array}\right]=\left[\begin{array}{c}
F_{P D, M, 6}\left[\begin{array}{l}
\sin ^{-1} \theta_{P D, 6} \\
\cos ^{-1} \theta_{P D, 6}
\end{array}\right] \\
F_{P D, M, 6}
\end{array}\right]
$$

Based on the calculation of force resultant in each piezoelectric sensor point, the position vector of $\mathrm{ZMP}\left(P_{P D,(x, y, z)}\right)$ based on CoP will be obtained by using (14-16):

$$
\begin{aligned}
& P_{P D, x}=\left(P_{P D, 1(x)}+P_{P D, 2(x)}+P_{P D, 3(x)}\right)-\left(P_{P D, 4(-x)}+P_{P D, 5(-x)}+P_{P D, 6(-x)}\right) \\
& P_{P D, y}=\left(P_{P D, 1(y)}+P_{P D, 5(y)}+P_{P D, 6(y)}\right)-\left(P_{P D, 2(-y)}+P_{P D, 3(-y)}+P_{P D, 4(-y)}\right)
\end{aligned}
$$




$$
P_{P D, z}=\sum_{i=1}^{i=6} P_{P D, i, z} / 6
$$

Where $P_{P D, 1}, P_{P D, 2}, P_{P D, 3}, P_{P D, 4}, P_{P D, 5}$, and $P_{P D, 6}$ is resultant force vector (X-Y-Z-axis) of piezoelectric sensor in each point of feet. $F_{P D, M, 1}, F_{P D, M, 2}, F_{P D, M, 3}, F_{P D, M, 4}, F_{P D, M, 5}$, and $F_{P D, M, 6}$ is pressure force value which applied in each piezoelectric sensor. $\theta_{P D, 1}, \theta_{P D, 2}, \theta_{P D, 3}, \theta_{P D, 4}, \theta_{P D, 5}$, and $\theta_{P D, 6}$ is certain angle in each piezoelectric sensor point to the origin point of robot feet. $P_{P D, x}, P_{P D, y}, P_{P D, Z}$ is position vector of ZMP based on CoP.

\subsection{Hardware framework of foot sensor module}

The hardware framework of foot pressure sensor module is shows in Figure 9. Where the output of piezoelectric sensor $\left(V_{O u t, A v, P D}\right)$ as input for the SLAVE block. The SLAVE block is a hardware with integrated micro-processor such as AVR or ARM. The data from piezoelectric sensor $\left(V_{O u t, A v, P D}\right)$ is processed by using resultant force method to obtaining the position vector of ZMP $\left(P_{P D,(x, y, z)}\right)$ and send it through serial communication (UART) to the MASTER block. MASTER block is a hardware with high speed clock such as mini-PC or laptop.

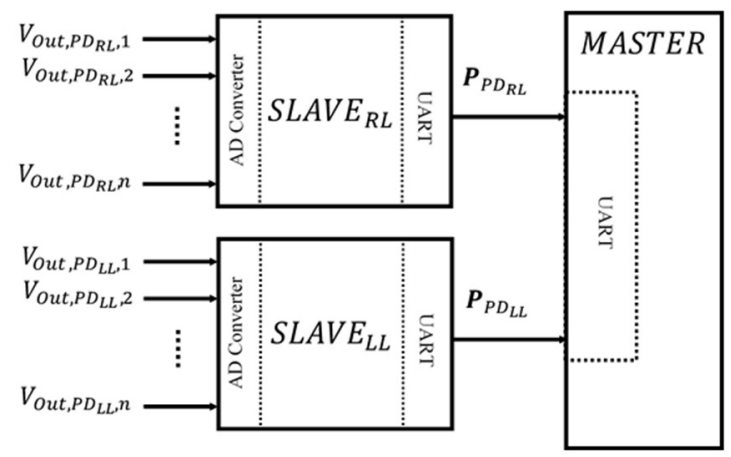

Figure 9. Hardware framework and comunication process

\section{RESULTS AND ANALYSIS}

This section is explaining an implementation results of foot sensor modul using piezoelectric sensor. Several experiments such as walk in place, walk in place with forward force disturbance, and walk in place with right side force disturbance was implemented into T-FLoW humanoid robot. In the explanation in subsection, the analysis is focused into the main issue of disturbance. During walk in place experiment, the analysis is focused in the position vector of ZMP based on CoP calculation in the X-axis. It is because the position vector of ZMP based on CoP in $\mathrm{Y}$-axis is undominant. During walk in place with forward force disturbance experiment, the analysis is focused in the position vector of ZMP based on CoP calculation in the $\mathrm{X}$-axis similar with walk inplace experiment. During walk in place with right side force disturbance experiment, the analysis is focused in the position vector of ZMP based on CoP calculation in the Y-axis because position vector of ZMP based on $\mathrm{CoP}$ in $\mathrm{Y}$-axis is dominant. Those experiments were doing with same walking locomotion parameters and in the flat floor (flat base).

\subsection{Walk in place}

This sub-section is explaining an implementation result of foot sensor modul using piezoelectric sensor during walking locomotion (walk in place). The implementation process is shown in Figure 10 and the result of foot sensor module calculation (position vector of ZMP based on CoP) is shown in Figure 11 .

Figure 10 is shows the walking locomotion process in the normal condition (without disturbance). T-FLoW humanoid robot needs 1.5 second to doing 1 full step of walk. From Figure 11, the calculation of position vector of ZMP based on CoP has maximum and minimum value (range) at $16 \mathrm{~mm}$ until $-22 \mathrm{~mm}$. The average value in positive area (forward direction in $\mathrm{X}$-axis) has value at $0.8 \mathrm{~mm}$ and the average value in negative area (backward direction in X-axis) has value at $-1.1 \mathrm{~mm}$. From this data, the final conclusion of T-FLoW humanoid robot during walk in place has dominant characteristic walk in place with backward direction (with comparison about $-0.3 \mathrm{~mm}$ ). 


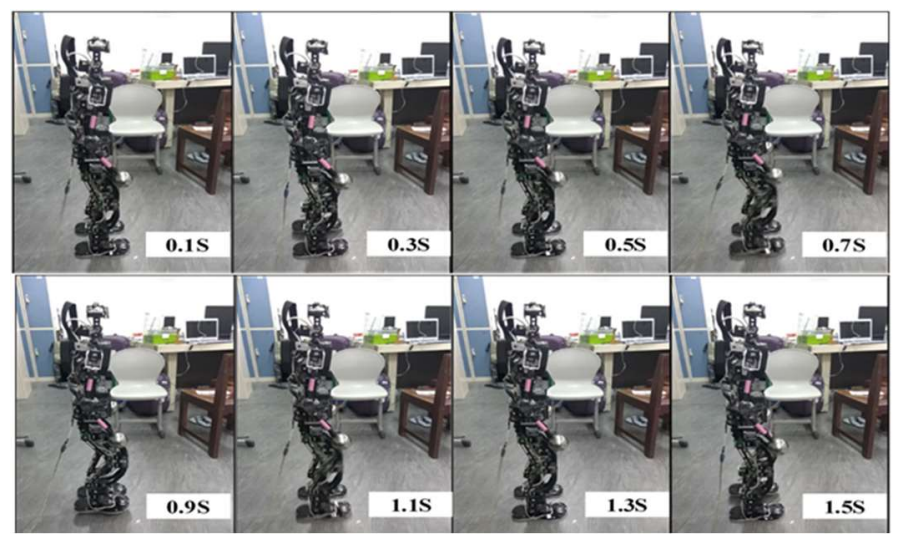

Figure 10. Implementation process of foot sensor module using piezoelectric sensor during walking locomotion (walk in place)

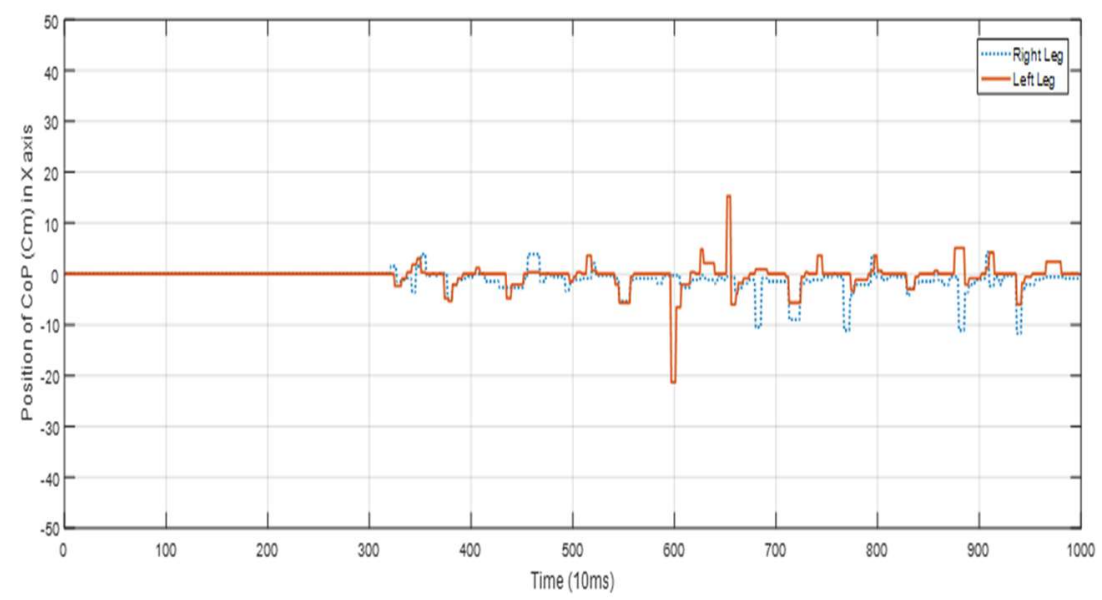

Figure 11. Position vector of ZMP based on CoP calculation during walk in place (without disturbance)

\subsection{Walk in place with forward force disturbance}

This sub-section is explaining an implementation result of foot sensor modul using piezoelectric sensor during walking locomotion (walk in place with forward force disturbance). The implementation process is shown in Figure 12 and the result of foot sensor module calculation is shown in Figure 13.

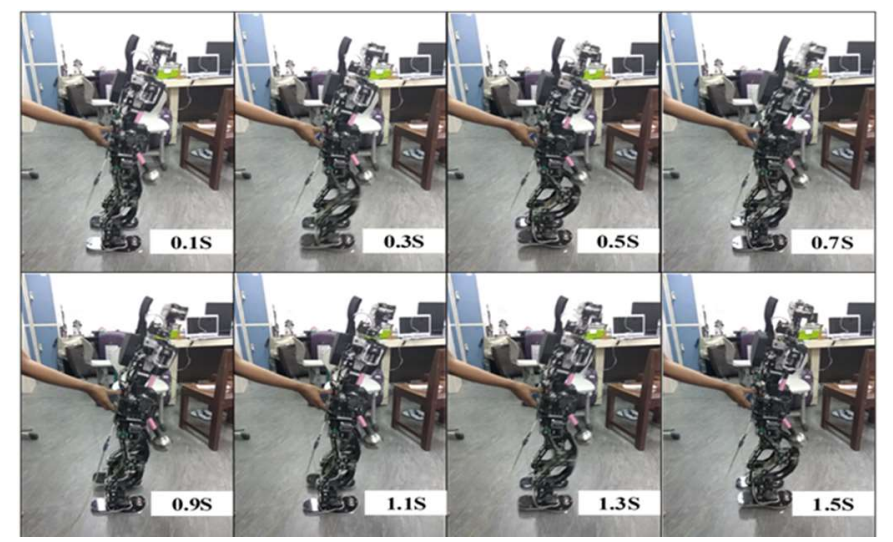

Figure 12. Implementation process of foot sensor module using piezoelectric sensor during walking locomotion (walk in place with forward force disturbance) 


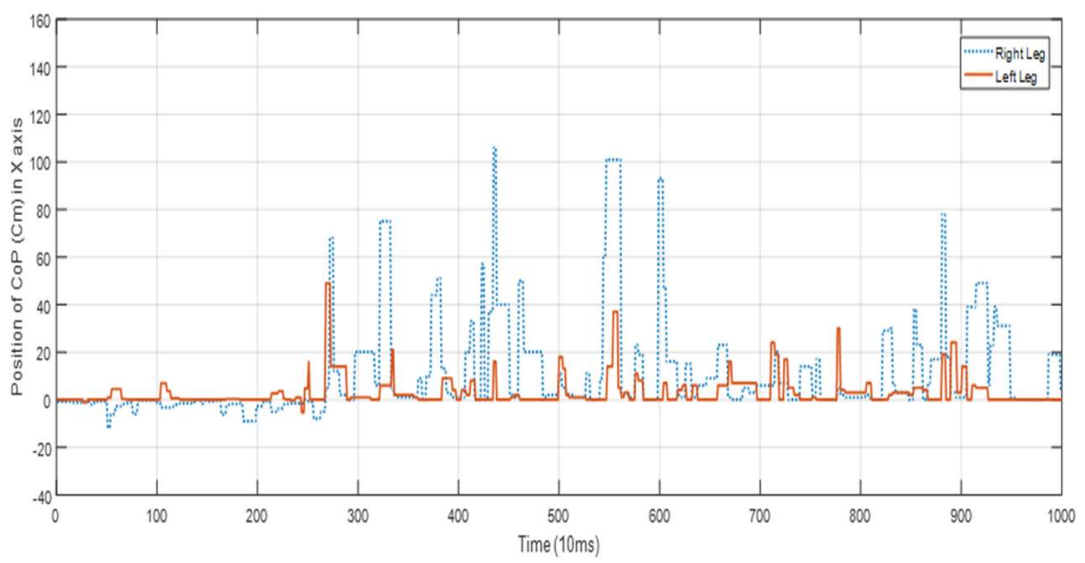

Figure 13. Position vector of ZMP based on CoP calculation during walk in place with forward force disturbance

Figure 12 is shows the walking locomotion process with forward force disturbance (with disturbance). T-FLoW humanoid robot needs 1.5 second to doing 1 full step of walk same with previous experiment. From Figure 13, the disturbance is applied during $275 \sim 960$ of time periode. The calculation of position vector of ZMP based on CoP has maximum and minimum value (range) at $108 \mathrm{~mm}$ until $-2 \mathrm{~mm}$. The average value in positive area (forward direction in $\mathrm{X}$-axis) has value at $86 \mathrm{~mm}$ and the average value in negative area (backward direction in X-axis) has value at $-0.04 \mathrm{~mm}$. From this data, the final conclusion of T-FLoW humanoid robot during walk in place has dominant characteristic walk in place with forward direction (with comparison about $85.96 \mathrm{~mm}$ ).

\subsection{Walk in place with right side force disturbance}

This sub-section is explaining an implementation result of foot sensor modul using piezoelectric sensor during walking locomotion (walk in place with right side force disturbance). The implementation process is shown in Figure 14 and the result of foot sensor module calculation is shown in Figure 15.

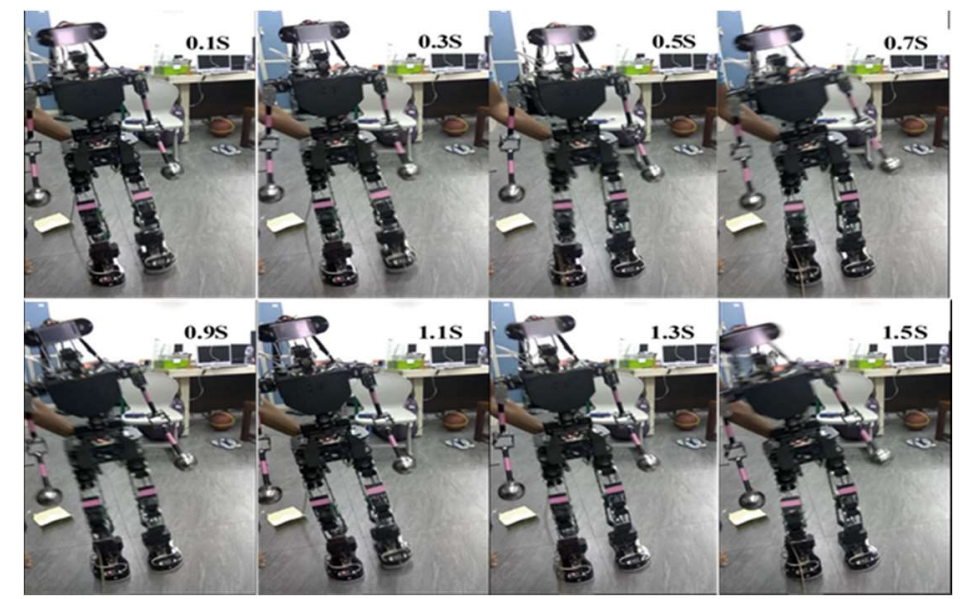

Figure 14. Implementation process of foot sensor module using piezoelectric sensor during walking locomotion (walk in place with right side force disturbance)

Figure 14 is shows the walking locomotion process with right side force disturbance (with disturbance). T-FLoW humanoid robot needs 1.5 second to doing 1 full step of walk same with previous experiment. From Figure 15, the disturbance is applied during 250 1180 of time periode. The calculation of position vector of ZMP based on CoP has maximum and minimum value (range) at $28 \mathrm{~mm}$ until $-72 \mathrm{~mm}$. The average value in positive area (left side direction in Y-axis) has value at $1.4 \mathrm{~mm}$ and the average value in negative area (right side direction in Y-axis) has value at $-68 \mathrm{~mm}$. From this data, the final conclusion of 
T-FLoW humanoid robot during walk in place has dominant characteristic walk in place with right side direction (with comparison about $-66.6 \mathrm{~mm}$ ).

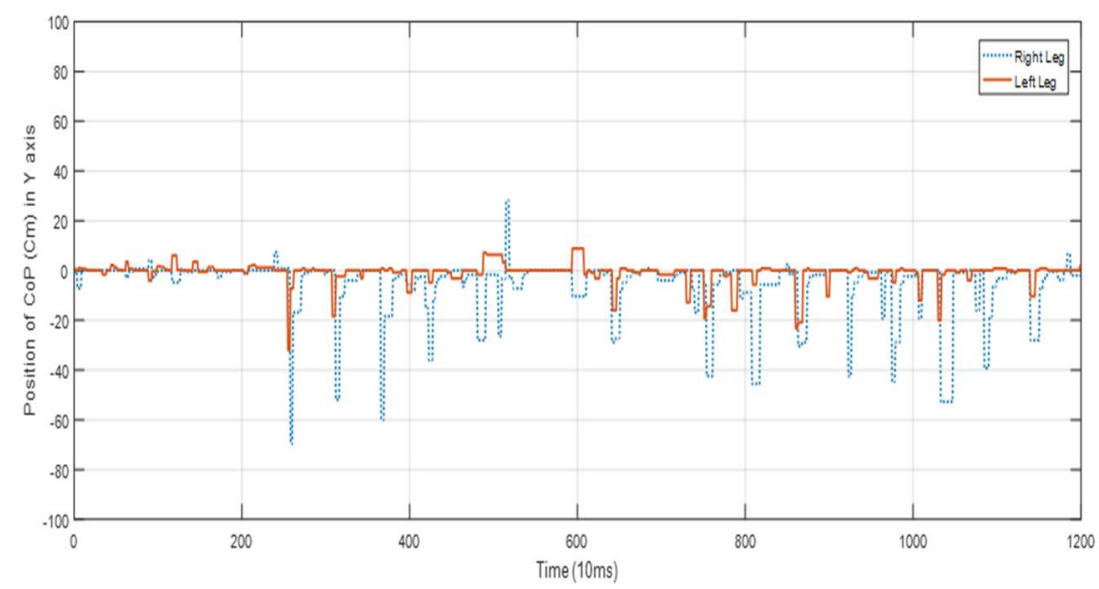

Figure 15. Position vector of ZMP based on CoP calculation during walk in place with right side force disturbance

\section{CONCLUSION}

From the 3 experiment which has been done. The final conclusion in first experiment is T-FLoW humanoid robot during walk in place has dominant characteristic walk in place with backward direction (with comparison about $-0.3 \mathrm{~mm}$ ). The final conclusion in second experiment is T-FLoW humanoid robot during walk in place has dominant characteristic walk in place with forward direction (with comparison about 85.96 $\mathrm{mm}$ ). The final conclusion in third experiment is T-FLoW humanoid robot during walk in place has dominant characteristic walk in place with right side direction (with comparison about $-66.6 \mathrm{~mm}$ ). Based on those final conclusions in each experiment, the implementation of foot pressure sensor modul using piezoelectric sensor has a good result (94\%) as shown in final conclusions in each experiment. The advantages of this new foot pressure sensor modul is low-cost design and similar result with another sensor such as flex sensor, loadcell sensor, and torque sensor. The disadvantages of this sensor are needed to recalculation because of the main characteristic of piezoelectric sensor (non-continuous read). Because of it, sometimes the calculation has outlayer data such as in the third experiment. But overall, the proposed model of foot pressure sensor modul in this research is work fine and already implemented in T-FLoW humanoid robot.

\section{ACKNOWLEDGEMENTS}

Gratefulness to Ministry of Research, Technology and Higher Education of the Republic of Indonesia for financial support, EEPIS Robotics Research Center (ER2C) laboratory, and Politeknik Elektronika Negeri Surabaya.

\section{REFERENCES}

[1] R. Dimas Pristovani, W. M. Rindo, B. Eko Henfri, K. H. Achmad Subhan, and Dadet Pramadihanto, "Basic walking trajectory analysis in FLoW Robot", In Proc. of 2016 International Electronics Symposium (IES), IEEE Press, New York, pp. 333-338, 2016.

[2] R. Dimas Pristovani, B. Eko Henfri, Dewanto. Sanggar, Pramadihanto. Dadet, "Walking Strategy Model based on Zero Moment Point with Single Inverted Pendulum Approach in "T-FLoW" humanoid robot", In Proc. Of 2nd International conferences on Information Technology, Information Systems and Electrical Engineering (ICITISEE), IEEE Press, New York, pp. 217-222, 2017.

[3] R. Dimas Pristovani, D. Raden Sanggar, and Pramadihanto. Dadet "Implementation of Push Recovery Strategy using Triple Linear Inverted Pendulum Model in "T-FloW" Humanoid Robot", in IOP Journal of Physics: Conference Series, vol. 1007, pp. 1-13, 2018.

[4] Ertie Abana, Kym Harris Bulauitan, Ravy Kim Vicente, Michelle Rafael, Jay Boy Flores, "Electronic Glove: A Teaching Aid for the Hearing Impaired", In International Journal of Electrical and Computer Engineering (IJECE), vol.8, no.4, pp. 2290-2298, 2018. 
[5] Godwin Ponraj Joseph Vedhagiri, Hongliang Ren, "Sensor Fusion of Leap Motion controller and Flex sensors using Kalman filter for Human finger tracking", In IAES International Journal of Robotics and Automation (IJRA), vol. 6 , no. 3, 2017.

[6] Haibin CHEN, Yi WANG, Liying ZHANG, Guangyu YANG, Xin NING, Xuemei CHENG, Zhengguo WANG, "Liquid Metal Strain Gage to Test Cervical Facet Capsule Strain", In Proc. Indonesian Journal of Electrical Engineering and Computer Science, vol.11, no.1, pp. 448-457, 2013.

[7] Gomez. S. O. C, "Sensing With A 3-Toe Foot For A Mini-Biped Robot," in Thesis Book, The Department of Electrical and Computer Engineering, Electrical And Computer Engineering, Northeastern University Boston, Massachusetts, 2014.

[8] Ott. C, Roa. M. A, and Hirzinger. G, "Posture And Balance Control For Biped Robots Based On Contact Force Optimization ", In Proc. 2011 11th IEEE-RAS International Conference on Humanoid Robots, IEEE, Bled, Slovenia, pp. 26-33, 2011

[9] Girão. P.S, Ramos. P. M. P, Postolache. O, and Pereira. J. M. D, "Tactile sensors for robotic applications," in Elsevier Journal: Measurement, vol. 46, pp. 1257-1271, 2013.

[10] Ha. I, Tamura. Y, Asama. H, Han. J, and Hong. D. W, "Development of Open Humanoid Platform DARwIn-OP", in Proc. SICE Annual Conference 2011, Waseda University, Tokyo, Japan, 2011, pp. 2178- 2181.

[11] Luneckas. M, Luneckas. T, and Udris. D, "Leg Placement Algorithm for Foot Impact Force Minimization," in International Journal of Advanced Robotic System, vol. 15, no. 1, pp. 1-10, 2018.

[12] Montes. H, Nabulsi. S, and Armada. M. A, "Reliable, Built-in, High-Accuracy Force Sensing for Legged Robots", in International Journal of Robotic Research - IJRR, vol. 25, no. 9, pp. 931 - 950, 2006.

[13] Ramana R G, Rao. A, Rambabu K, and Prakash K, "Simple and Cost Effective Foot Pressure Detection System for Diabetic Patients," in International Journal of Advanced Research in Electrical, Electronics and Instrumentation Engineering, vol. 6, no. 5, pp. 4070 - 4076, 2017.

[14] Dineva. P.S, Gross. D, Muller. R, and Rangelov. T, "Dynamic Fracture of Piezoelectric Materials Solution of Time-Harmonic Problems via BIEM, Solid Mechanics and Its Applications 212," Springer International Publishing Switzerland, pp. 7-31, 2014.

[15] Jayant Sirohi and Inderjit Chopra, "Fundamental Understanding of Piezoelectric Strain Sensors", in Journal Ofintelligentmaterialsystems Andstructures, vol. 11, 2001, Technomic Publishing Co., Inc., pp. 246 - 257, 2000.

[16] Crawley. E. F, and J. de Luis, "Use of Piezoelectric Actuators as Elements of Intelligent Structures", in AIAA Journal, vol. 25, no. 10, pp. 1373-1385, 1987.

[17] Anderson. E. H. and N. W. Hagood, "Simultaneous Piezoelectric Sensing/Actuation: Analysis and Application to Controlled Structures," in Journal of Sound and Vibration, vol. 174, no. 5, pp. 617-639, 1994.

[18] Esteban. J, F. Lalande, and C. A. Rogers, "Parametric Study on the Sensing Region of a Collocated PZT ActuatorSensor," in Proc. 1996 SEM VIII International Congress on Experimental Mechanics, 1996.

[19] Hanagud. S, M. W. Obal, and A. J. Calise. "Optimal Vibration Control by the Use of Piezoelectric Sensors and Actuators," in Journal of Guidance, Control and Dynamics,vol. 15, no. 5, pp. 1199-1206, 1992.

[20] Inman. D. J, J. J. Dosch, and E. Garcia, "A Self-Sensing Piezoelectric Actuator for Collocated Control," in Journal of Intelligent Materials and Smart Structures, vol. 3, pp. 166-185, 1992.

[21] Kreuger. H. H. A, "Stress Sensitivity of Piezoelectric Ceramics: Pt. I. Sensitivity to Compressive Stress Parallel to the Polar Axis," in Journal of the Acoustical Society of America, vol. 42, pp. 636-645, 1967.

[22] Kreuger. H. H. A. "Stress Sensitivity of Piezoelectric Ceramics: Pt. III. Sensitivity to Compressive Stress Perpendicular to the Polar Axis," in Journal of the Acoustical Society of America, vol. 43, pp. 583-591, 1968.

[23] Lee. C. K. and T. O'Sullivan, "Piezoelectric Strain Rate Gages, " in Journal of the Acoustical Society of America, vol. 90, no. 2, pp. 945-953, 1991.

[24] Lee. C. K, T. C. O'Sullivan, and W. W. Chiang, "Piezoelectric Strain Rate Sensor and Actuator Designs for Active Vibration Control," in Proc. of the 32nd AIAA/ASME/ASCE/AHS/ASC Structures, Structural Dynamics and Materials Conference, no 4, pp. 2197-2207, 1991.

[25] Lin. M. W and C. A. Rogers, "Modeling of the Actuation Mechanism in a Beam Structure with Induced Strain Actuators," in Proc. AIAA-93-1715-CP, 1993.

[26] Lin. M. W, and C. A. Rogers. "Bonding Layer Effects on the Actuation Mechanism of an Induced Strain Actuator/Substructure System," in Proc. SPIE, vol. 2190, pp. 658-670, 1994.

[27] Mattiat. O. E, "Ultrasonic Transducer Materials, Plenum Press," New York, 1971.

[28] Qui. J, and J. Tani, "Vibration Control of a Cylindrical Shell Using Distributed Piezoelectric Sensors and Actuators," in Journal of Intelligent Material Systems and Structures, vol. 6, no. 4, pp. 474-481, 1995.

[29] Samuel. P, and D. Pines, "Health Monitoring/Damage Detection of a Rotorcraft Planetary Geartrain Using Piezoelectric Sensors," in Proc. of SPIE's 4th Annual Symposium on Smart Structures and Materials, San Diego, CA, 3041, pp. 44-53, 1997.

[30] Stout. D. F, "Handbook of Operational Amplifier Circuit Design, McGraw-Hill Book Company," 1976.

[31] Varadan. V. K, X. Bao, C.-C. Sung, and V. V. Varadan, "Vibration Control of Flexible Structures Using Piezoelectric Sensors and Actuators, " in Journal of Wave-Material Interaction, vol. 4, no. 1-3, pp. 65-81, 1989. 


\section{BIOGRAPHIES OF AUTHORS}
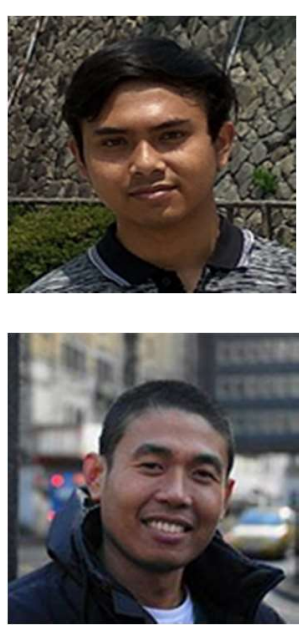

Dimas Pristovani Riananda received an Associate Degree (3 Years), Bachelor's degree, and Master's Degree in Electrical Engineering from Electronics Engineering Polytechnics Institute of Surabaya (EEPIS) / Politeknik Elektronika Negeri Surabaya (PENS). He was joined in the EEPIS Robotics Research Center (ER2C) Laboratory on humanoid robot division and receive several achievements in national and international level. His areas of interest include development of humanoid / human like robots, kinematics and dynamics system, control system, and electronics development.

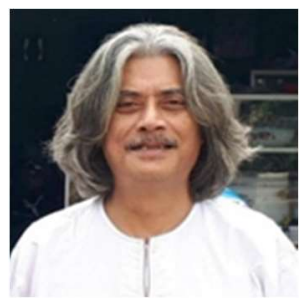

Raden Sanggar Dewanto received his Bachelor's and Master's degree in Electronics Engineering from Sepuluh Nopember Institute of Technology. He received Doctor of Philosophy in Control System Engineering from Newcastle University, UK. He now Lecturer in Mechatronics Engineering Department - Electronics Engineering Institute of Surabaya (EEPIS) and supervisor member of EEPIS Robotics Research Centre (ER2C). His areas of interest include development of humanoid / human like robots, kinematics and dynamics system, control system, mechanical design and analysis, and development of mems.

Dadet Pramadihanto received a Bachelor Degree in Control and Instrumentaion Engineering from Sepuluh Nopember Institute of Technology and receive Master of Engineering and Doctor of Philosophy in Computer vision from Osaka University Japan in 1997 and 2003. He now Lecturer in Computer Engineering Department - Electronics Engineering Institute of Surabaya (EEPIS) and head of EEPIS Robotics Research Centre (ER2C). His areas of interest include development of humanoid / human like robots, real-time robotics operating systems, computer vision in robotics, and engineering education based on robotics technology. 